\title{
Electrochemical Corrosion Properties of 316LSS and Titanium in Various Corrosion Media \\ D. Bubesh Kumar
}

\begin{abstract}
The work was carried on biomedical implants and the selection of correct methods for corrosion studies and study of the corrosion products, electrochemical methods are used to determine the metal and alloys corrosion rate and to characterize the corrosion damage. Microscopy and spectroscopy studies are used for characterization and determination of thickness and nature of the corrosion products.
\end{abstract}

Keywords: Corrosion, Titanium \& 316L SS

\section{INTRODUCTION}

The corrosion of metallic biomaterials in artificial body fluid, and investigated the corrosion behaviour of commercially pure titanium (CP-Ti), Ti-6Al-4V) and 316L stainless steel 316LSS in Hanks solution at $38^{\circ} \mathrm{C}$ using the cyclic polarization test. Corrosion behaviour is described in terms of breakdown potential at the rate of corrosion, localized corrosion resistance and breakdown repassivation. It is concluded that CP-Ti used in this study has the lowest corrosion rate and corrosion potential whereas 316LSS showed lower passive current density than CP-Ti and Ti-6Al-4V. Anodized CP-Ti is used in human body due to its lower corrosion rate as higher corrosion potential coupled with the absence of localized corrosion. CP- Ti has low strength than other grades of titanium. Further work can be carried on Titanium grades 2, 3 and 4. Many researchers have conducted on immersion corrosion test, electrochemical corrosion test, fatigue corrosion test and also effects of corrosion on biometals. Pitting corrosion of metals with and without inhibitors was studied. The electrochemical polarization test Nyquist plot showed titanium have more corrosion resistant than other bio-metals.

\section{METHODOLOGY}

\section{A. Electrochemical Corrosion Test}

Electrochemical Corrosion test is conducted on metals. This test is a rapid corrosion test. The test was conducted for 30 minutes electrochemical corrosion apparatus.

The tests are carried out on plate of dimensions $1.0 \mathrm{~cm}$ $\mathrm{x} 4.0 \mathrm{~cm} \quad \mathrm{x} \quad 2 \mathrm{~cm}$ Electrochemical measurement on biomaterials is performed at $37^{\circ} \mathrm{C}$ in ringer Solution. A conventional three electrode electrochemical cell system is

Revised Manuscript Received on January 15, 2020.

*Correspondence Author

D. Bubesh Kumar*, Associate Professor, Department of Mechanical Engineering, AVIT, Chennai, Tamil Nadu, India. Email: bubeshkumar@avit.ac.in

(C) The Authors. Published by Blue Eyes Intelligence Engineering and Sciences Publication (BEIESP). This is an open access article under the CC BY-NC-ND license (http://creativecommons.org/licenses/by-nc-nd/4.0/) used in Saturated Calomel Electrode (SCE), Platinum mesh is used as reference and Counter electrodes respectively In the experiments, the Open Circuit Potential (OCP) is measured for an hour.

Electrochemical impedance is usually measured by applying an AC potential to an electrochemical cell and measuring the current through the cell. Electrochemical Impedance is normally measured using a small excitation signal of 10 to $50 \mathrm{mV}$.

\section{EXPERIMENTS AND RESULTS}

The material is tested for chemical composition and its corrosion resistance.

Table 1: Chemical Composition of 316L SS

\begin{tabular}{|l|l|l|l|l|l|}
\hline \multicolumn{7}{|c|}{ Steel 316L } \\
\hline $\mathrm{C}$ & 0.021 & $\mathrm{~S}$ & 0.002 & $\mathrm{Ni}$ & 14.10 \\
\hline $\mathrm{Mn}$ & 1.68 & $\mathrm{P}$ & 0.015 & $\mathrm{Mo}$ & 2.51 \\
\hline $\mathrm{Si}$ & 0.71 & $\mathrm{Cr}$ & 17.20 & $\mathrm{~N}$ & 0.060 \\
\hline $\mathrm{Fe}$ & Bal & \multicolumn{5}{|l|}{} \\
\hline
\end{tabular}

The 316 LSS chemical composition is given in table: 1 and mechanical properties of 316 LSS are shown in the table: 2

Table 2: Mechanical Properties of 316L SS

\begin{tabular}{|c|c|}
\hline Properties & 316L SS \\
\hline Young's Modulus & $210 \mathrm{GPa}$ \\
\hline Poisson's ratio & 0.3 \\
\hline
\end{tabular}

The tests is conducted on metals and alloys having the following surfaces ground-average roughness $R_{a}=0.31 \mu \mathrm{m}$. To measure the roughness the surfronic $3+$ surface analyser is applied. The electrochemical test is conducted on the metal showed pitting of 316L SS metal specimen. The electrochemical corrosion tests are recorded in anodic polarization curve. The CHI Electrochemical workstation with impedance, Model 660A System for electrochemical tests are used in the tests. The metal is immersed into the artificial body solution for 30min and made to open circuit potential $\left(\mathrm{E}_{\mathrm{ocp}}\right)$ stabilized. Then the potentiodynamic polarization is performed. From the polarization study corrosion parameter such as corrosion potential ( $\left.\mathrm{E}_{\text {corr }}\right)$, Corrosion Current ( $\mathrm{I}_{\text {corr }}$ ) and Tafel slopes (anodic ba and cathodic bc ) are calculated. All the experiments are repeated for three times. The tests are carried out in various corrosion media used in Implants and fixators.

Published By:

Blue Eyes Intelligence Engineering \& Sciences Publication 
Table 3: Electrochemical Test Results on 316 LSS

\begin{tabular}{|c|c|c|c|}
\hline System & $\begin{array}{c}\text { Ecorr } \\
\text { mv vs } \\
\text { SCE }\end{array}$ & Bc mv/decay & $\begin{array}{c}\text { ba } \\
\text { mv/decay }\end{array}$ \\
\hline Seawater + SS 316L & -430 & 0.1257 & 0.2506 \\
\hline $\begin{array}{l}\text { Seawater + SS 316L + } \\
\text { Creatinine }\end{array}$ & -228 & 0.1875 & 0.0673 \\
\hline Ringer Soln. + 316L SS & -128 & 0.0672 & 0.4430 \\
\hline $\mathrm{NaOH}$ & -347 & .001 & 0.0058 \\
\hline Hank's Solution & -144 & 0.7131 & 0.1773 \\
\hline System & $\begin{array}{c}\text { LPR } \\
\text { ohmcm }^{2}\end{array}$ & $\begin{array}{l}\text { Icorr } \\
\mathbf{A} / \mathbf{c m}^{2}\end{array}$ & \\
\hline Seawater + SS 316L & $\begin{array}{c}7.5565 \\
\times 10^{7} \\
\end{array}$ & $4.8102 \times 10^{-10}$ & \\
\hline $\begin{array}{l}\text { Seawater + SS 316L + } \\
\text { Creatinine }\end{array}$ & $\begin{array}{c}6.3090 \\
\times 10^{8}\end{array}$ & $3.41 \times 10^{-11}$ & \\
\hline Ringer Soln. + 316L SS & $\begin{array}{c}102433 \\
0666\end{array}$ & $2.4736 \times 10^{-10}$ & \\
\hline $\mathrm{NaOH}$ & 283 & $8.8660 \times 10^{-6}$ & \\
\hline Hank's Solution & 286384 & $2.1536 \times 10^{-7}$ & \\
\hline
\end{tabular}

Table 4 Nyquist plot for 316LSS

\begin{tabular}{|l|r|l|}
\hline \multirow{2}{*}{ System } & \multicolumn{2}{|c|}{ Nyquist plot } \\
\cline { 2 - 3 } & Rt ohm $/ \mathbf{c m}^{2}$ & $\mathbf{C F} / \mathbf{c m}^{2}$ \\
\hline Seawater+SS 316L & 66.05 & $1.7938 \times 10^{-9}$ \\
\hline $\begin{array}{l}\text { Seawater+SS } \\
\text { 316L+ Creatinine }\end{array}$ & 147.25 & $1.2203 \times 10^{-11}$ \\
\hline
\end{tabular}

The table 3 gives the electro chemical tests results on 316 LSS

The table 4 gives the Nyquist plot for 316 LSS.

\section{Analysis of Polarization Curve 316L SS}

The potentiodynamic polarization curves of 316L stainless steel metal immersed in 5\% sodium hydroxide solution, Hank's solution, sea water, Ringer solution these are shown in Figures 1,2, 3, 4. The corrosion parameters are corrosion potential (Ecorr), Tafel slopes (bc= cathodic), (ba = anodic), linear polarization resistance (LPR) and corrosion current (Icorr). The corrosion resistance of a metal in a corrosion medium increases, LPR (Linear Polar Resistance) value increases and the corrosion current decreases. From the corrosion analysis of 316L SS metal specimen in 5\% $\mathrm{NaOH}$, the corrosion current is $8.866 \times 10^{-6} \mathrm{~A} \mathrm{~cm}^{-2}$ and the LPR value is $283 \Omega \mathrm{cm}^{2}$. Then 316L SS metal is immersed in Hank's solution, the corrosion current is decreased from $8.866 \times 10^{-6} \mathrm{~A} \mathrm{~cm}^{-2}$ to $2.1536 \times 10^{-7} \mathrm{~A} \mathrm{~cm}^{-2}$ and the LPR value is increased from $283 \Omega \mathrm{cm}^{2}$ to $286384 \Omega \mathrm{cm}^{2}$. The 316L SS metal is immersed in seawater the corrosion current is decreased from $2.1536 \times 10^{-7} \mathrm{~A} \mathrm{~cm}^{-2}$ to $4.8102 \times 10^{-8}$ and the LPR value is increased from $286384 \Omega \mathrm{cm}^{2}$ to $754744 \Omega$ $\mathrm{cm}^{2}$. The 316L SS metal specimen in Ringer solution the corrosion current was decreased from $4.8102 \times 10^{-8} \mathrm{~A} \mathrm{~cm}^{-2}$ to $2.4736 \times 10^{10}$ and the LPR value is increased from $754744 \Omega$ $\mathrm{cm}^{2}$ to $102430666 \Omega \mathrm{cm}^{2}$. The above results shows that $316 \mathrm{~L}$ SS is more corrosion resistance in Ringer solution than seawater, Hank's solution and $5 \% \mathrm{NaOH}$. The tests also shows formation of protective film on the 316L SS metal surface.
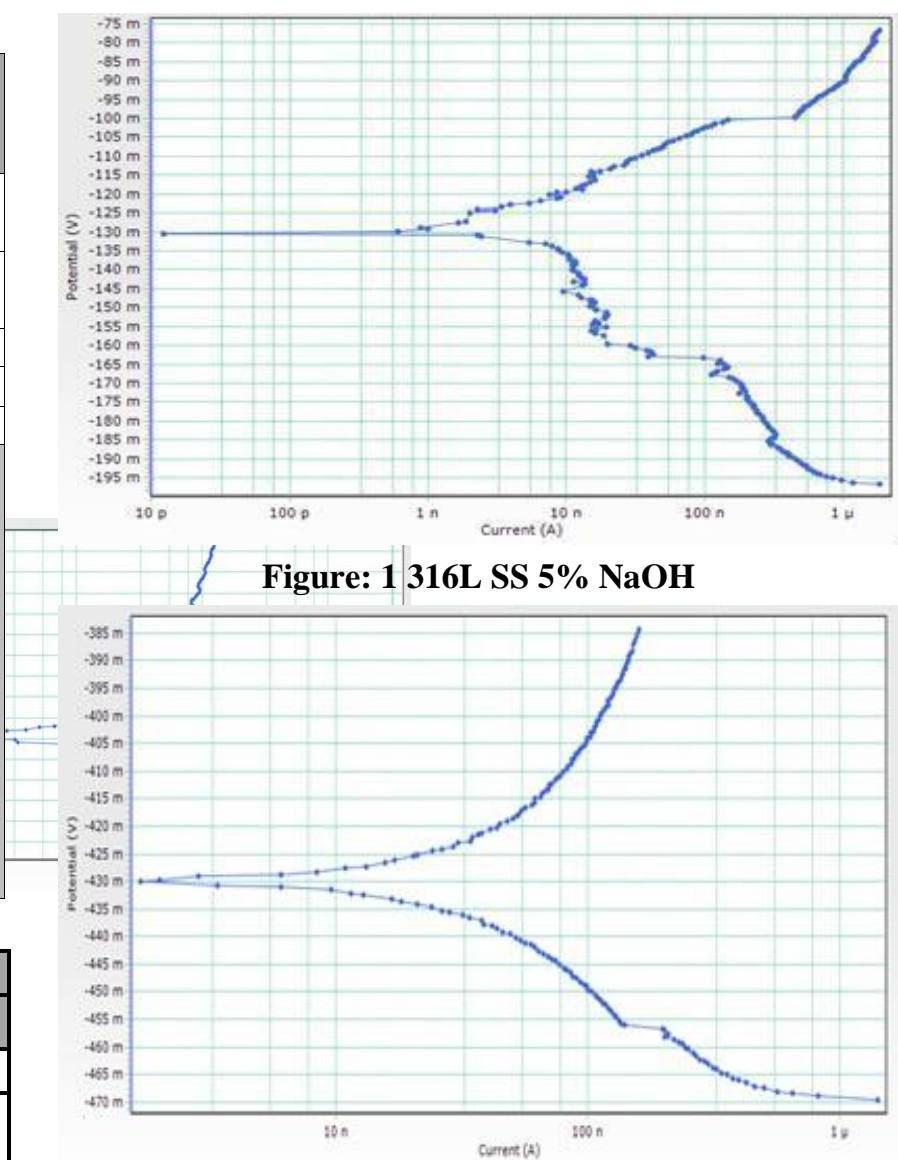

Figure: 2 316L SS + Hanks Solution

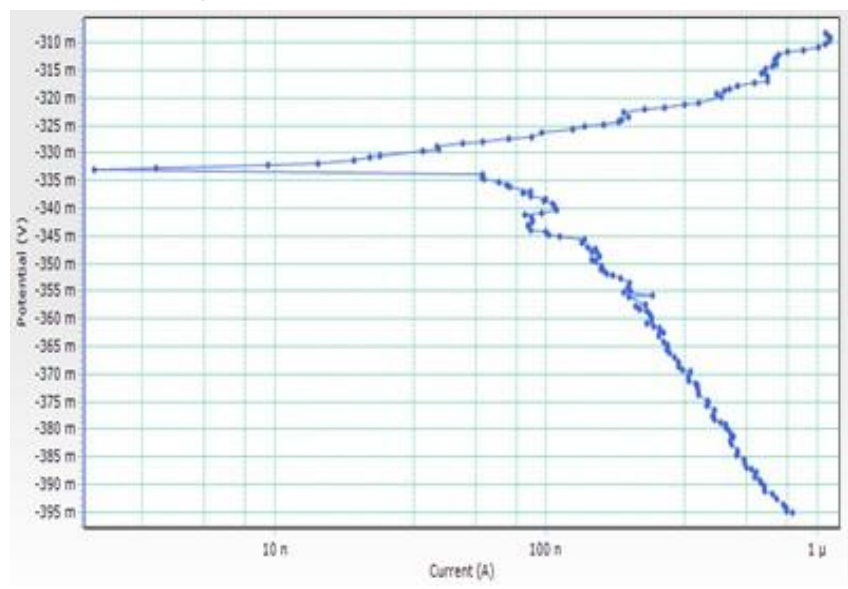

Figure: 3 316L SS + Sea Water

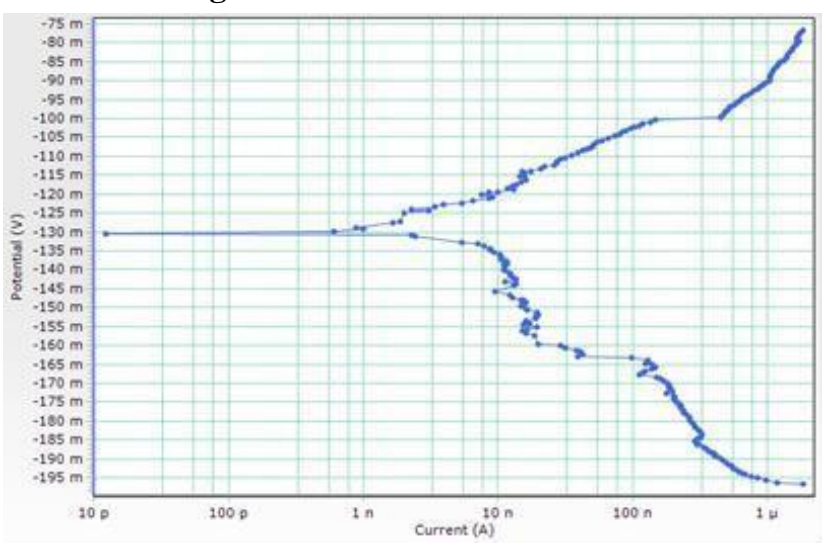

Figure: 4: 316L SS + Ringer Solution 


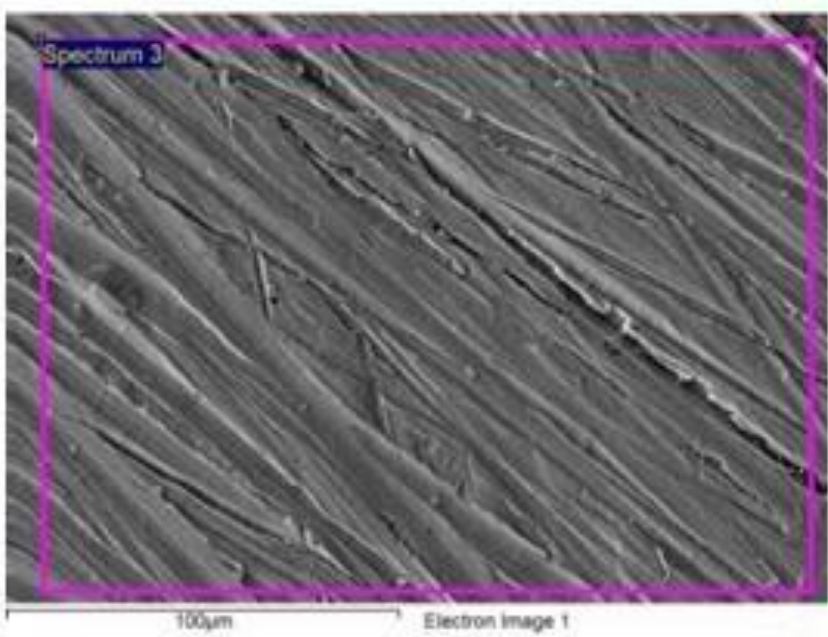

Figure 5: SEM Analysis Electrochemical Corrosion Tests on 316L SS

The above figure:5 results show the SEM Analysis on 316L SS in ringer solution. The surface is seen as thick bands showing the presence of corrosion.

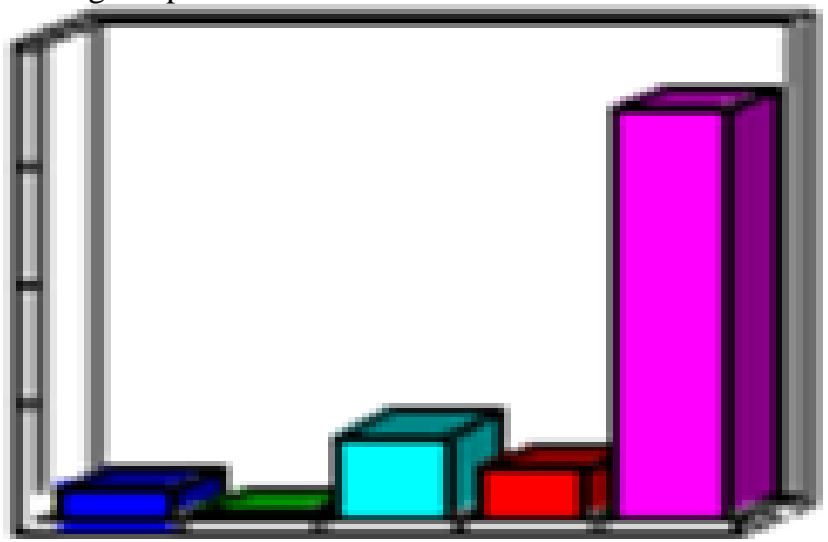

Figure 6: Bar chart Weight \% of 316LSS

The Figure 6 shows the bar chart for weight percentage of 316LSS after electrochemical Corrosion Test. The figure 6 bar chart shows the weight \% of 316L SS metal immersed in ringer solution. The percentage of oxygen is seen in the figure 6 , this indicates the presence. of corrosion..

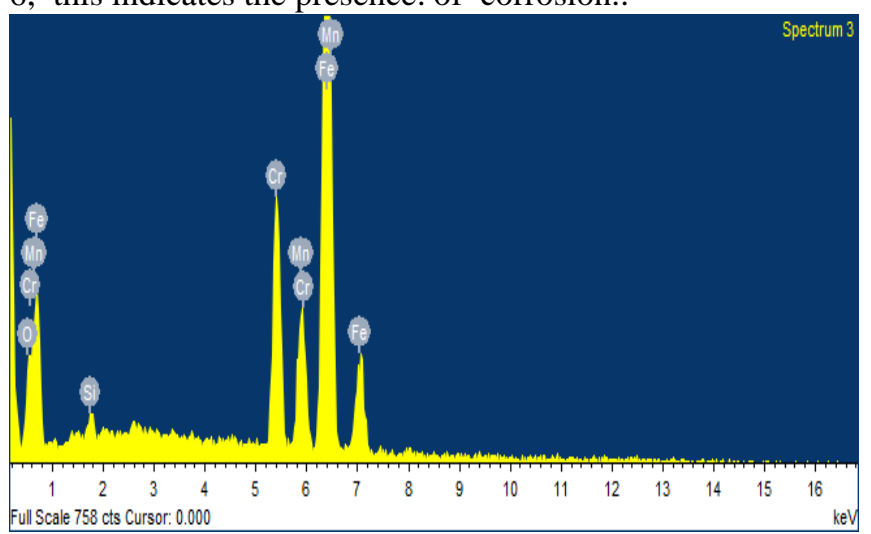

Figure 7: EDAX of 316L SS Eletrochemical Corrosion Test

The figure 7 shows EDAX of 316L SS metal. The 316L SS immersed in ringer solution. The corrosion products chloride is seen as white colour.

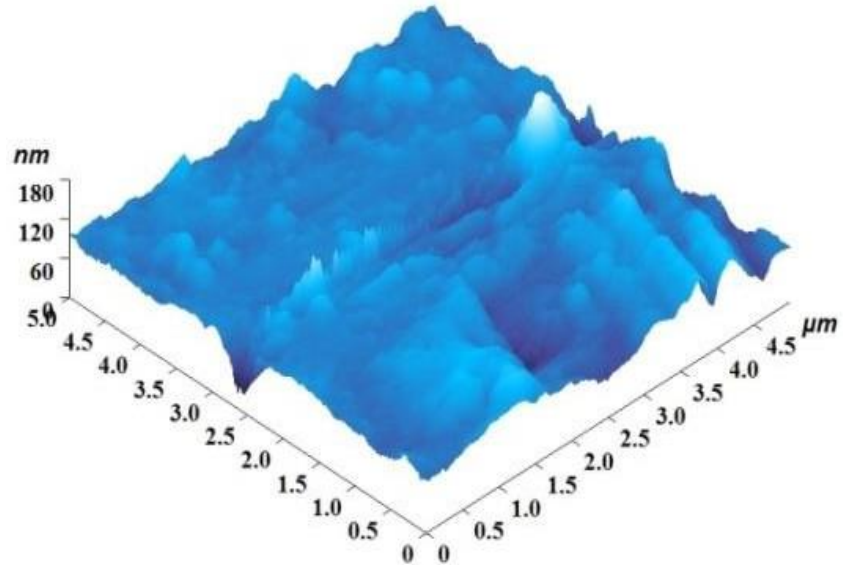

Figure 8: AFM of 316L SS Electrochemical Corrosion Test, Ringer Solution

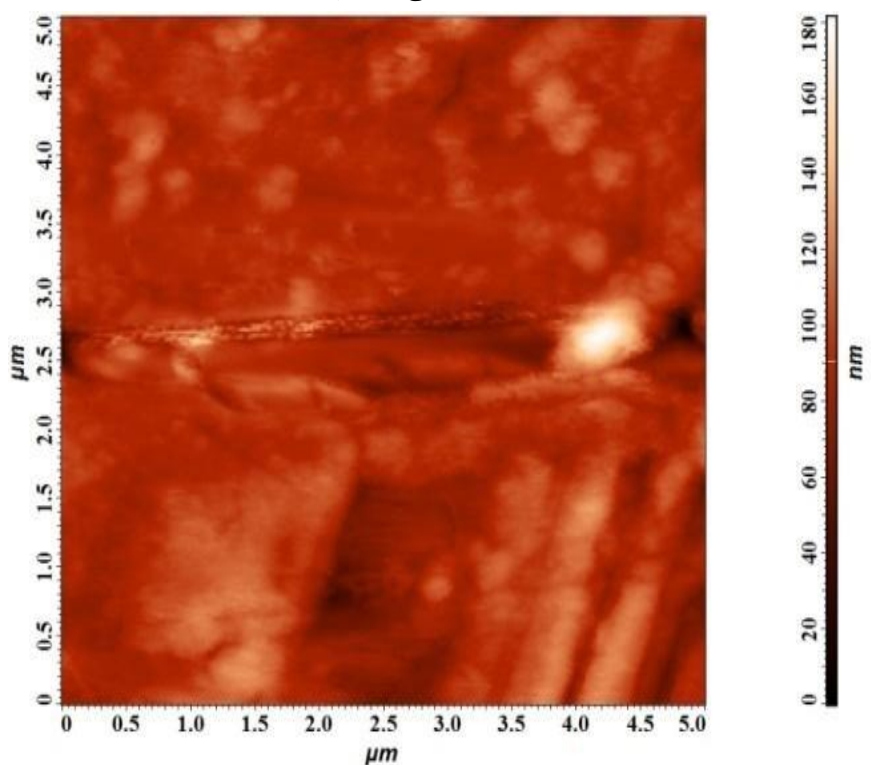

Figure 9: Graph AFM of 316L SS Electrochemical Corrosion Test Ringer Solution

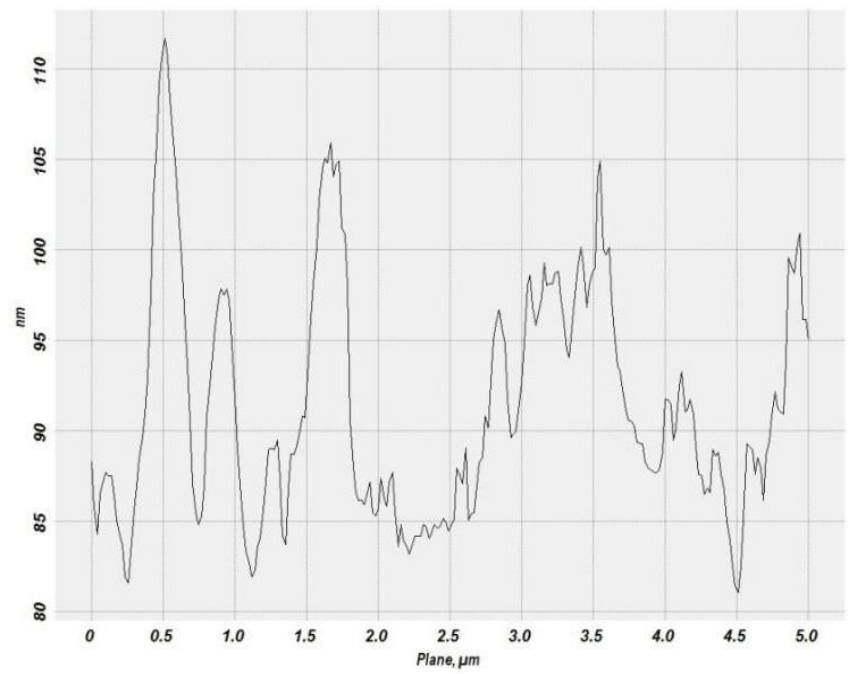

Figure 10: Graph Shows Roughness Analysis Graph for 316L SS immersed in Ringer Solution

Figure 8, 9 shows the 2D and 3D Atomic force microscope Images

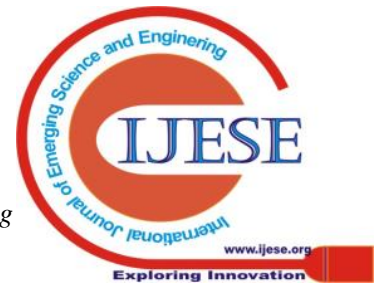


Table 5: Surface Analysis for 316L SS

\begin{tabular}{|c|l|l|}
\hline S.No & Surface Analysis & Values \\
\hline 1 & Amount of sampling & 65536 \\
\hline 2 & Max & $181.374 \mathrm{~nm}$ \\
\hline 3 & Min & $0 \mathrm{~nm}$ \\
\hline 4 & Peak-to-peak, Sy & $181.374 \mathrm{~nm}$ \\
\hline 5 & Ten point height, Sz & $90.9423 \mathrm{~nm}$ \\
\hline 6 & Average & $91.3529 \mathrm{~nm}$ \\
\hline 7 & Average Roughness, Sa & $9.36504 \mathrm{~nm}$ \\
\hline 8 & Root Mean Square, Sq & $13.3928 \mathrm{~nm}$ \\
\hline 9 & Second moment & 8524.72 \\
\hline 10 & Surface skewness, Ssk & 0.511014 \\
\hline 11 & Coefficient of kurtosis, & 4.70375 \\
\hline 12 & Ska & 8.80241 \\
\hline 13 & Entropy & -0.174461 \\
\hline
\end{tabular}

The above figure10 shows roughness analysis of 316L SS metal immersed in ringer solution. The peaks and valleys are seen in the graph. The values of surface analysis is given in the table 5. The entropy value 8.80241 indicates corrosion.

\section{CONCLUSION}

It is concluded from the above results the polarization curve for the 316L SS is more corrosion resistance in ringer solution than the sea water. From this we infer the 316L SS metal will corrode in blood. We infer that the chemical composition of 316L SS may be altered by adding more chromium in the 316L SS alloy to reduce corrosion when implanted in the human body. The SEM analysis and the AFM results shows that the corrosion as occurred on the 316L SS specimen.

\section{REFERENCES}

1. Robert Wen-Wei Hsu, Chun-Chen Yang, Ching-An Huang, Yi-Sui Chen, "Investigation on the corrosion behaviour of Ti-6Al-4V implant alloy by electrochemical techniques". Materials chemistry and physics 2004, 86 269-278.

2. W. Kajzer, A. Krauze, W. Walke, J. Marciniak. Corrosion resistance of Cr-Ni-Mo steel in simulated body fluids. Journal of achievements in materials and manufacturing Engineering. September-October2006. Volume 18, issue1-2.

3. Kkochnim Oh, SooHoon Ahn, KwangsupEom, Hyuksang Kwon. A study on the localized corrosion and repassivation Kinetics of fe-20Cr-XNi $(X=0-20 w t \%)$ stainless steels via electrochemical analysis. K.Oh at. Corrosion science XXX, 2015, pp.350-354.

4. Zuojia LIU, Xuequn Cheng, shengjie LU and Xiaogang LI. Effect of chloride ions $316 \mathrm{~L}$ stainless steel in cyclic cooling water. ActaMetall.sin.(Eng.Lett.),December 2010,Vol. 23 No.6 pp.431-438.

5. Kkochnim Oh, SooHoonAhn, KwangsupEom, Hyuksang Kwon. A study on the localized corrosion and repassivation Kinetics of fe-20Cr-XNi(X=0-20wt\%) stainless steels via electrochemical analysis. K.Oh at./ Corrosion science XXX, 2015, p.11.

6. Seifedine Kadry, Corrosion Analysis of Stainless Steel, European Journal of Scientific Research, ISSN 1450-216X, 2008,Vol.22No.4 pp.508-516.

7. Z. Ahmadian, IDanaee, M.A. Golozar. Effect of surface treatment on corrosion resistance of 304 stainless steel implants in tyrode solution, February 2013, volume 59,20.

8. Hamid Reza AsgariBidhendi, Majidpouranvari.Association of metallurgical engineers of Serbia AMES,metalurgija-Mjom, 2011, vol. 17 (1) p.13-22.

9. W. Walke, Z. Paszenda, A. Ziebowicz. Corrosion behaviour of Co-Cr-W-Ni alloy in diverse body fluids, Achive of materials Science and Engineering. 2007, vol.28,15.04.

10. Lei Yang, Erlin Zhang. Biocorrosionbehavir of magnesium alloy in different simulated fluids for biomedical application. Materials science and Engineering C 2009, 29 1691-1696.

11. Meisam Salahshoor and Yuebin Gue. Biodegradable Orthopedic
Magnesium-Calcium(MgCa) alloys, Processing, and Corrosion Performance. Materials 2012, 5, pp:135-155.

12. GeethaManivasagam, Durgalakshmi Dhinasekaran and Asokamani Rajamanikam. "Biomedial Implants: Corrosion and its Prevention-A Review” Recent Patents on Corrosion Science.2010, Volume 17, pp.40-54.

\section{AUTHOR'S PROFILE}

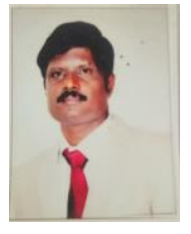

Dr. D. Bubesh Kumar, is working as Associate Professor in the Department of Mechanical Engineering. He has Published more than 15 research papers, He has written a book in the area of Fatigue corrosion of Biomaterials. He has applied for 5 patents out of which three patents are three patents are awaiting for examinations. He has guided more than 90 projects for UG students and 10 projects for PG Students. His Ph.D Scholars are pursuing research in the field of composites, additive manufacturing and Biomechanics. 